\title{
Determinação da Umidade de Solo pelos Métodos Estufa e Forno Micro-Ondas em Diferentes Texturas de um Latossolo Vermelho- Amarelo Sul-Amazônico
}

\author{
Determination of Soil Moisture by Methods Greenhouse and Microwave in Different Textures \\ of a Red-Yellow Oxissoil in Amazon South
}

Determinación de la Humedad del Suelo por los Métodos Invernadero y Horno Microondas en Diferentes Texturas de un Latosol Rojo-Amarillo del Sur de la Amazonía

\author{
Salem Leandro Moura dos Santos ${ }^{1}$ \\ Eliomar Pereira da Silva Filho²
}

\begin{abstract}
RESUMO: Este estudo objetiva avaliar a secagem de solo entre o padrão estufa com fornos microondas de diferentes potências, com destaque para análises de diversas texturas de solos e as interações dos óxidos de ferro com as micro-ondas. Para tanto, foi avaliada a correlação e o nível de significância dos valores de umidade de solo, em porções de 100 gramas de texturas arenosa, argilosa e muito argilosa em estufa por 24 horas à temperatura de $\pm 105^{\circ}$ Celsius e em dois fornos micro-ondas de diferentes potências reais a $100 \%$ de sua eficiência por cinco minutos. Além disto, foi procedida a análise do Índice de Vermelho das amostras para avaliação da existência de óxidos de ferro. Verificou-se um índice de correlação positivo de desidratação das amostras de $R^{2}$ 0,97; entre estufa e micro-ondas, tanto para as amostras argilosas como para as arenosas, utilizando a potência real média de 494,31 w.j. $\mathrm{seg}^{-1}$. Conclui-se que o forno micro-ondas oferece uma elevada eficiência para a secagem de solo. Contudo devem ser observadas discretas deficiências de secagem de solos argilosos contendo óxidos de ferro, que reduzem o percentual de secagem das amostras muito argilosas em torno de $0,69 \%$, dada a dissipação das micro-ondas quando atingem os óxidos presentes nestes solos.
\end{abstract}

PALAVRAS-CHAVE: Gravimetria. Calibração. Óxidos.

ABSTRACT: This study aims to evaluate the rate of soil drying between the greenhouse standard and microwaves apparatus of different powers settings with an emphasis on different soil textures and the

\footnotetext{
1 Programa de Pós-Graduação em Geografia - PPGG - Universidade Federal de Rondônia - UNIR. BR 364, Km 9,5. CEP: 76801-059. Prédio do CEGEA. Laboratório de Geomorfologia e Pedologia, Porto Velho- RO. salemsantos@gmail.com.

2 Departamento de Geografia - DGEO - Universidade Federal de Rondônia - UNIR. BR 364, Km 9,5. CEP: 76801-059. Prédio do CEGEA. Laboratório de Geomorfologia e Pedologia, Porto Velho- RO. eliomarfilho@uol.com.br.
} 
iron oxides interactions at different microwaves powers settings. The measurement of correlation and significance level of moisture present in 100 grams of samples soils of textures sandy, clay and very clayey was analyzed at a temperature of $\pm 105^{\circ} \mathrm{C}$ during 24 hours, using greenhouse and microwaves ovens with powers settings at 100\% the operational efficiency for 5 minutes. In addition, the Red Index of samples was analyzed by iron oxides presence. A Pearson positive correlation dehydration coefficient of $R^{2}$ 0,97; in the samples between greenhouses and microwaves and for clay as well as sandy samples was found, using the average real power of $494.31 \mathrm{w} \cdot \mathrm{j} \cdot \mathrm{seg}^{-1}$. It is concluded that microwaves oven shows a high efficiency to drying soil. However, discrete drying deficiencies in clay soils containing iron oxides were observed, which decrease the drying percentage of the samples analyzed in around $0.69 \%$, due the microwaves dissipation when they reach the oxides present in these soil.

KEYWORDS: Gravimery. Calibration. Oxide.

RESUMEN: Este estudio objetivo evaluar la secado de suelo entre el estándar invernadero con hornos microondas de diferentes potencias, con destaque para análisis de diferentes texturas de suelos y las interacciones de los óxidos de hierro con las microondas. Se evaluaron la correlación y el nivel de significancia de los valores de humedad de $100 \mathrm{~g}$ de texturas: arenosa, arcillosa y muy arcillosa en invernadero por 24 horas a la temperatura de $\pm 105^{\circ}$ Celsius y en dos hornos microondas de diferentes potencias reales, al 100\% de su eficiencia por 5 minutos. Además, se procedió al análisis del Índice de Rojo de las muestras para evaluar la presencia de óxidos de hierro. Se verificó un índice de correlación positiva de Pearson de deshidratación de las muestras de $R^{2}$ 0,97; entre invernadero y microondas, tanto para las muestras arcillosas como para las arenosas, utilizando la potencia real media de $494,31 \mathrm{w} \cdot \mathrm{j} \cdot \mathrm{seg}^{-1}$. Se concluye que el microondas es una óptima alternativa para el secado de suelo. Sin embargo, deben observarse discretas deficiencias de secado de suelos arcillosos que contiene óxidos de hierro que disminuyen el porcentaje de secado de estas muestras en torno al 0,69\%, debido a la disipación de las microondas cuando alcanzan los óxidos presentes en estos suelos.

PALABRAS-CLAVE: Gravimetría. Calibración. Óxidos.

\section{INTRODUÇÃO}

O conhecimento da distribuição do teor de água (umidade) no solo torna-se cada vez mais necessário, uma vez que está intimamente ligado às propriedades do sistema solo, água, planta, cultivo, produção e uso da terra. O manejo do recurso de água deve ser feito no sentido de torná-lo disponível para a sociedade de forma adequada, buscando o melhor uso social e econômico (TRINTINALHA et al., 2004).

Embora a umidade do solo seja um conceito físico comum, apresenta dificuldades na sua determinação, de forma a se obter um valor representativo devido à inerente variabilidade espacial e temporal das características físicas do solo (TRINTINALHA et al. 2004). Diversos são os métodos para determinação da umidade do solo, contudo o método padrão é o de avaliação por estufa. Para tal determinação é necessário que as amostras de 
solo permaneçam em estufa por um período de 24 horas em temperatura a $\pm 105^{\circ} \mathrm{C}$, com o resultado de elevada precisão, não havendo a necessidade de calibração, segundo a EMBRAPA (1997). Porém, o tempo gasto para sua execução é considerado longo. O uso da estufa gera um alto consumo de eletricidade, além do mais contribui para um gasto excessivo de tempo até que se obtenha uma amostra pronta para leitura dos dados.

Para contornar esses problemas, há outros métodos, alternativos, como: Speedy Test (PAIVA NETTO; MEDINA, 1953), frigideira (TAVEIRA et al., 2016) e o forno micro-ondas. Eles possuem o mesmo objetivo: a diminuição do tempo e de energia para obtenção da umidade do solo, ainda assim os métodos da frigideira e Speedy Test apresentam menor precisão ao método padrão do que o forno micro-ondas, com coeficiente de correlação de $\mathrm{R}^{2}$ 0,88 para o Speedy Test (RIBEIRO et al., 2018) e correlação inversa para a frigideira em tempos acima de 10 minutos (TAVEIRA et al., 2016).

O uso do forno micro-ondas para avaliação da umidade do solo é uma técnica eficaz e simples, e ela pode aumentar a eficiência de amostragem com igual precisão ao método convencional. Miller, Smith e Biggar (1974) propuseram o uso do forno de micro-ondas doméstico, que pode diminuir o tempo de secagem, pois o custo de aquisição do forno micro-ondas é inferior aos das estufas de ventilação forçada, que são as indicadas para secagem, pois distribuem de maneira uniforme o aquecimento. O valor comercial entre os equipamentos pode variar entre centenas a milhares de reais (EQUIPEX, 2018). Esse relativo tempo está sempre atrelado à função do número de amostras, do tamanho e da potência do forno, do teor de umidade inicial, da massa da amostra e do tipo de solo analisado, para que possa valer a economia de tempo e de energia no processo de secagem do solo. Neste caso, o tipo de solo analisado para o procedimento de secagem foi o Latossolo Vermelho-Amarelo Distrófico localizado na bacia do Igarapé Belmont em Porto Velho - Rondônia.

O objetivo deste estudo é o de avaliar a relação de secagem de solo entre o padrão estufa com fornos micro-ondas de diferentes potências em relação a diferentes texturas e as interações dos óxidos de ferro com as micro-ondas.

\section{AS MICRO-ONDAS}

As radiações eletromagnéticas de micro-ondas são radiações não ionizantes, cuja frequência está compreendida entre $300 \mathrm{MHz}$ a $300 \mathrm{GHz}$. São derivadas da energia elétrica, podendo ser facilmente manipuladas através de folha metálica, que reflete as ondas, refrata em uma interface dielétrica de moléculas ou focaliza por meio de refletores parabólicos ou antenas (MAGALHÃES; LIMA; SOUZA, 2003). 
As micro-ondas podem aquecer moléculas de água, através da transformação da energia da onda eletromagnética em energia térmica. $O$ aquecimento é baseado na associação da dissipação de energia interna e da excitação molecular de dipolos em um campo eletromagnético, o que permite uma taxa de aquecimento mais elevada e uniforme (DIAS, 2013).

Segundo Berteli (2005), Silva, Ferreira e Souza (2006) e Pereira (2007), a tecnologia de micro-ondas oferece grandes benefícios na secagem de materiais, tais como menor tempo e maior eficiência de secagem.

Para gerar as micro-ondas, os fornos de micro-ondas utilizam uma válvula (magnetron). Ela consiste em um dispositivo sob vácuo, que converte energia elétrica em micro-ondas. Uma diferença de potencial constante é aplicada entre o ânodo (que é um cilindro circular oco) e o cátodo. Os elétrons são acelerados do cátodo para o ânodo, mas a presença de um forte campo magnético (produzido por um eletroímã colocado entre os dois polos) faz com que os elétrons descrevam uma trajetória curva e sigam um caminho em espiral, produzindo rádio frequência. Posteriormente, ocorre a emissão de ondas eletromagnéticas por uma antena colocada diretamente sobre o ânodo (BARBOZA et al., 2001). Essa válvula, como característica geral, sofre desgaste com o uso, apresentando perda de potência de emissão de ondas e queimas.

\section{MODO DE AQUECIMENTO VIA MICRO-ONDAS}

O modo de aquecimento por micro-ondas não deve ser concebido como uma forma de energia calórica, mas sim como uma forma de energia de onda eletromagnética. Ao absorver a onda eletromagnética, o material bombardeado apresenta como efeito principal em suas moléculas a rotação dipolar, que pode ser descrita pelo modelo da molécula de água, que apesar de ter carga elétrica total nula, apresenta-se como um dipolo elétrico, pois o centro de gravidade das cargas positivas não coincide com o das cargas negativas, como a molécula apresenta um lado de maior afinidade positiva e outro lado de afinidade negativa (Figura 1), (PEREIRA, 2007).

Figura 1 - Configuração do dipolo da água em seu desequilíbrio de cargas

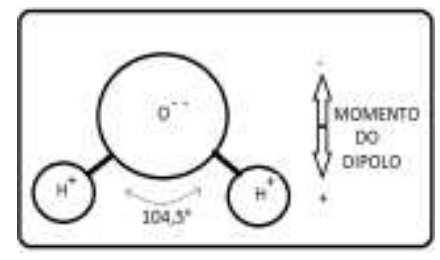

Fonte: Autores. 
Sob a ação de um campo elétrico externo, esse mesmo dipolo tende a girar, orientando-se na direção da carga campo. Sendo assim, a rotação dipolar consiste na interação da onda eletromagnética com as moléculas do material que possuem dipolo elétrico. Por serem polares, essas moléculas, na presença de um campo magnético, tendem a se alinhar com este campo. Se o campo for oscilante, como é o caso das ondas eletromagnéticas de oscilações rápidas, nas frequências de giga-hertz, essas moléculas irão girar continuamente para se alinhar ao campo. Esse fenômeno é conhecido como rotação de dipolo. Com a alternância do campo magnético, as moléculas vão invertendo sua orientação e, concomitantemente, essas moléculas colidem com outras moléculas e átomos adjacentes, gerando atrito e energia calórica (SCHMITT, 2002).

Além da colisão entre moléculas, a rotação do dipolo encontra resistência em seu próprio eixo, que tende a ser inerte, o que resulta em dissipação de energia eletromagnética do campo, sob forma de calor, com consequente aumento de temperatura molecular (MAGALHÃES; LIMA; SOUZA, 2003).

Segundo Barboza et al. (2001) a quantidade de calor produzido depende da constante dielétrica (magnetron), do tamanho das moléculas e de sua viscosidade, contudo a dissipação de energia que gera calor é influenciável pela temperatura inicial do material, pois a temperatura faz com que as moléculas tenham mais ou menos atritos entre si, devido ao efeito de compactação e dilatação da matéria, como também é necessária mais energia para tirar as moléculas da inércia, para realizar sua rotação para o alinhamento dipolar, o que justifica a necessidade da estabilidade de temperatura nas amostras a serem analisadas.

Pereira (2007) menciona que as propriedades dielétricas do material a ser aquecido em forno micro-ondas afetam diretamente o mecanismo de interação entre este material e o campo elétrico aplicado. Em contraste com os métodos convencionais de aquecimento, onde o transporte de calor da superfície para o centro se dá 10 a 20 vezes mais lentamente, o aquecimento por micro-ondas leva à geração de calor instantâneo dentro do material, devido, primariamente, ao atrito molecular e por causa da ruptura de pontes fracas de hidrogênio, associadas com a rotação dos dipolos de moléculas de água livre.

Ao observar o comportamento de secagem por micro-ondas, Magalhães, Lima e Souza (2003) perceberam que, assim como na estufa, o aquecimento eleva-se rapidamente no início do processo. Em seguida, a retirada da umidade ocorre lentamente até estabilizarse para ter a velocidade diminuída à medida que a quantidade de água reduz. Dias (2013) concluiu que a perda acentuada de água no início da secagem é causada pela evaporação da água mais superficial nos solos, gerando uma camada de vapor sob pressão entre moléculas, causando maior eficiência na secagem, contudo, ao diminuir o percentual de 
Determinação da Umidade de Solo pelos Métodos Estufa e Forno Micro-Ondas em Diferentes...

água no solo, essa camada gasosa se extingue dificultando a eficiência da secagem por ondas.

\section{TIPOS DE POTÊNCIA ELÉTRICA}

A potência do aparelho micro-ondas é distinguida em potência de consumo e potência de saída, pois existe diferença entre elas. Sendo assim, a potência de consumo leva em consideração a energia consumida pela válvula magnetron para criar as micro-ondas, a alimentação do ventilador ressonador de ondas, a alimentação dos circuitos de controle e mais a energia enviada para o objeto a ser esquentada em forma de onda, por isso a potência de consumo sempre será maior que a potência de saída, que é a potência unicamente enviada em forma de ondas para aquecer o objeto no interior do aparelho, também chamada de potência útil (VIANA et al., 2012). Um exemplo disto é o forno microondas Electrolux MEF28, que consome uma potência de $1140 \mathrm{~W}$, porém a potência de saída é de 700W. Verifica-se uma grande diferença entre as potências (INMETRO, 2017).

\section{MODOS DE SECAGEM DE SOLO E INFLUÊNCIA MINERALÓGICA}

Verifica-se em vários estudos um padrão de uso aproximado de tempo de cinco minutos e diferentes potências dos diversos aparelhos micro-ondas empregados na secagem dos solos com relação ao método padrão estufa $\pm 105^{\circ} \mathrm{C}$ por 24 horas de secagem. Segundo Tavares et al. (2008) as argilas reagem mais às ondas eletromagnéticas do aparelho do que as areias que tem a configuração monopolar, necessitando de menos tempo para a secagem, dada a sua configuração dipolar (Figura 1).

Ao analisar o comportamento de solos do tipo Latossolo Amarelo e Latossolo Vermelho Amarelo, Cremon et al. (2014) concluíram que eles diferem dos demais quando utilizado o forno micro-ondas para desidratação dos mesmos, dado à sua mineralogia. Por serem solos com elevado teor de oxi-hidróxido de ferro, em relação à outros, este mineral magnetizável reage com as micro-ondas, dispersando as moléculas d'água em agitação. Este efeito, segundo Tavares et al. (2008), estabelece diferentes patamares térmicos na amostra, podendo diferenciar o teor de umidade, se a amostra for exposta a pouco tempo de secagem, sem que alcance o ponto de estabilização de umidade ou se for seca em grandes quantidades de amostras (volume) no forno micro-ondas.

Sobre o estudo da reação das micro-ondas de frequência de $2,45 \mathrm{GHz}$ com relação aos diferentes tipos de óxidos, Wong (1975), Tinga (1989), e Koleini e Barani (2012), destacam que os diferentes óxidos reagem de maneira diferente ao serem bombardeados 
por micro-ondas, com alguns óxidos com comportamento não linear de aquecimento. Baseado na taxa de aquecimento de óxidos em fornos micro-ondas, Koleini e Barani (2012) puderam classificar os minerais em hiperativos, ativos, difíceis de aquecer e inativos (Quadro 1).

Quadro 1 - Relação de aquecimento de minerais sobre citação de micro-ondas

\begin{tabular}{|c|c|c|c|}
\hline \multicolumn{2}{|r|}{ Tipo de Mineral } & \multirow{2}{*}{$\begin{array}{c}\text { Taxa de aquecimento } \\
200^{\circ} \mathrm{C} / \mathrm{min} .\end{array}$} & \multirow{2}{*}{$\begin{array}{c}\text { Temp. Máxima } \\
500^{\circ}-1000^{\circ} \mathrm{C}\end{array}$} \\
\hline$\infty$ & $\left(\mathrm{Fe}_{3} \mathrm{O}_{2}\right)$ Magnetita & & \\
\hline 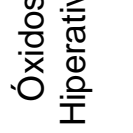 & $\left(\mathrm{FeS}_{2}\right)$ Pirita & $200^{\circ} \mathrm{C} / \mathrm{min}$. & $500^{\circ} \mathrm{C}$ \\
\hline \multirow{2}{*}{ 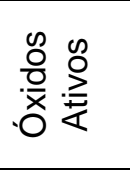 } & $\left(\mathrm{Ni}_{2} \mathrm{O}_{3}\right)$ Óxido de Níquel II & $400^{\circ} \mathrm{C} / \mathrm{min}$ & $1300^{\circ} \mathrm{C}$ \\
\hline & $\left(\mathrm{Fe}_{2} \mathrm{O}_{3}\right)$ Hematita & $170^{\circ} \mathrm{C} / \mathrm{min}$ & $1000^{\circ} \mathrm{C}$ \\
\hline \multirow{2}{*}{ 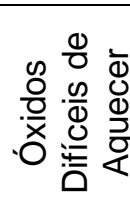 } & $\left(\mathrm{Al}_{2} \mathrm{O}_{3}\right)$ Óxido de Alumínio & $80^{\circ} \mathrm{C} / \mathrm{min}$. & $1900^{\circ} \mathrm{C}$ \\
\hline & (MgO) Óxido de Magnésio & $33^{\circ} \mathrm{C} / \mathrm{min}$. & $1300^{\circ} \mathrm{C}$ \\
\hline \multirow{2}{*}{ 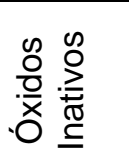 } & $\left(\mathrm{CaCO}_{3}\right)$ Carbonato de Cálcio & $5^{\circ} \mathrm{C} / \mathrm{min}$ & $130^{\circ} \mathrm{C}$ \\
\hline & $\left(\mathrm{SiO}_{2}\right)$ Sílica & 2 à $5^{\circ} \mathrm{C} / \mathrm{min}$. & $70^{\circ} \mathrm{C}$ \\
\hline
\end{tabular}

Fonte: Koleini e Barani (2012).

Pickles, Mouris e Hutcheon (2005), ao estudarem o comportamento dos hidróxidos de ferro sob alta temperatura em micro-ondas, em uma quantidade de 100 gramas, constataram que quando chegam a temperatura de $380^{\circ} \mathrm{C}$, em uma frequência de $2,46 \mathrm{Ghz}$, eles se alteram para uma nova composição mineralógica, desidratado, isto causado pela evaporação da água constituinte no minério, gerando a hidrohematita, que reage menos às ondas, devido a sua taxa de permissividade dielétrica ser de menor frequência. Os autores concluíram que o aquecimento da goethita apresenta um pico de temperatura e em seguida um decréscimo rápido, causado pela mudança de frequência de citação do minério. Deste modo, determina-se que enquanto as hematitas apresentam um aumento de temperatura linear, as goethitas apresentam picos de aquecimento, dado à perda de água.

Ao relacionar os óxi-hidróxidos de ferro com a cor do solo, Correia et al. (2008) constataram que as goethitas são mais abundantes que as hematitas, mesmo em solos de cor avermelhada (2,5YR), que apresentam predomínio de hematita, dada a sua maior estabilidade frente ao intemperismo e erosões.

Com relação ao tipo de solo, Fernandes et al. (2004) constataram que os Latossolo Vermelho Amarelo, nos horizontes $A$ e $B$, apresentam variações de matrizes entre $10 \mathrm{R}$ à $5 \mathrm{Y}$, dada a grande influência da quantidade de goethita. Quando isolada a goethita, sem a 
Determinação da Umidade de Solo pelos Métodos Estufa e Forno Micro-Ondas em Diferentes...

presença de hematita, o solo apresentou matriz maior que 7,5YR, o que se diagnostica é a influência dos hidróxidos de ferro com o padrão Mansell de cores.

Ao relacionar a goethita e hematita com o modo de secagem em micro-ondas, constata-se que o tempo de secagem deve variar conforme o percentual de óxi-hidróxidos de ferro no solo.

Buske et al. (2014) concluíram que o tempo de secagem de cinco minutos serve tanto para solos arenosos quanto para solos argilosos, com óxidos e hidróxidos de ferro, e é suficiente para se obter o mesmo valor de umidade em um método padrão estufa. Nesta análise verificou-se um coeficiente de correlação de $R^{2}$ 0,98 entre estufa e forno microondas de 900W de potência. A mesma correlação foi encontrada por Miranda et al. (2012) também com o tempo de cinco minutos.

Já Cremon et al. (2014) verificaram um tempo de seis minutos em potência máxima do aparelho de micro-ondas como o mínimo necessário para alcançar o mesmo valor de umidade obtida por secagem em estufa por 24 horas em temperatura de $\pm 105^{\circ} \mathrm{C}$, utilizando um micro-ondas de potência de 1.000W.

Em estudos sobre a secagem de Latossolos Vermelho Amarelo no Mato Grosso do Sul em profundidade de $0-20 \mathrm{~cm}$, Oliveira e Roque (2016) verificaram que foram necessários sete minutos em um aparelho de micro-ondas de 700w de potência real para igualar o teor de umidade das amostras com a secagem padrão estufa, com uma correlação de $R^{2} 0,96$, enquanto Sales et al. (2012) informaram que cinco minutos não é um tempo suficiente para secagem de acordo com o padrão estufa para solos argilosos, logo o tempo de 10 minutos em forno micro-ondas apresentou o melhor resultado para secagem. Os tempos de 10, 15, 20 e 25 minutos de secagem no micro-ondas não diferiram mais que $5 \%$ seus valores em relação ao método padrão, destacando o tempo de 10 minutos como o mais eficiente em termos de energia e tempo gastos para a secagem. A mesma utilizou 30 gramas de um solo com $45 \%$ de argila, $20 \%$ de areia e $35 \%$ de silte. Um solo com predominância de argila, porem só mencionou que foi utilizada potência alta do aparelho micro-ondas para o experimento, sem mais detalhes do tipo da potência e de seus valores, o que dificulta saber qual a potência real de aquecimento do forno.

Tavares et al. (2008) analisaram a perda de umidade de solos do tipo Latossolo Vermelho Distroférrico típico e o Latossolo Vermelho Distrófico. Os resultados das comparações de médias dos valores de umidade gravimétrica mostram que foi necessário apenas quatro minutos para atingir o mesmo nível de secagem do padrão estufa para um solo de textura argilosa. Porém para solos com predominância arenosa o tempo deve ser elevado, devido à baixa interatividade dos grãos de areia com as ondas do aparelho. Neste estudo, a forma de secagem do solo foi feita em potência máxima do aparelho utilizando 20 , 40 e 60 gramas de solo sem informar qual a potência em Watts e seu tipo. 
Um estudo mais detalhado foi feito por Miranda et al. (2008), que correlacionou o padrão estufa com diferentes potências de um mesmo forno micro-ondas na secagem de um solo arenoso (Tabela 1). O tempo padrão utilizado foi de cinco minutos para todas as amostras que variaram de 5 a 25 gramas. O aparelho micro-ondas de potência máxima de 1.280 Watts foi utilizado em várias potências para correlacionar com o padrão estufa $\pm 105^{\circ}$ Celsius em 24 horas. Porém não foi mencionado se a potência de $1.280 \mathrm{~W}$ é a potência de consumo ou a potência de saída do aparelho.

Tabela 1 - Relação de potência e perda de água de aparelho de micro-ondas

\begin{tabular}{c|c|c}
\hline Micro-ondas & Potência & Correlação \\
\hline $90 \%$ & $1.152 \mathrm{~W}$ & $\mathrm{R}^{2}=0,957$ \\
\hline $80 \%$ & $1.024 \mathrm{~W}$ & $\mathrm{R}^{2}=0,997$ \\
\hline $70 \%$ & $896 \mathrm{~W}$ & $\mathrm{R}^{2}=0,980$ \\
\hline $60 \%$ & $786 \mathrm{~W}$ & $\mathrm{R}^{2}=0,995$ \\
\hline $50 \%$ & $640 \mathrm{~W}$ & $\mathrm{R}^{2}=0,487$ \\
\hline
\end{tabular}

Fonte: Miranda et al. (2008).

Dias (2013) informa que na secagem por micro-ondas a condição que resulta no menor tempo de processo e, portanto, maior velocidade da perda de água, foi na potência alta do aparelho, necessitando de quatro minutos e 30 segundos em média para a secagem de 2,3kg de amostra de base de argila. A taxa de secagem média foi igual a 0,008 (água/g.ss.min). Na condição de potência baixa, o tempo médio e a taxa de secagem equivalente foram iguais a 14,5 minutos e 0,001 (g.min).

Quanto ao gasto energético, Dias (2013) chegou à conclusão de que a estufa apresenta um consumo de energia maior por massa de produto seco quando em comparação com o forno micro-ondas, além de necessitar de mais tempo para realizar a secagem.

\section{ÁREAS DE LOCALIZAÇÃO AMOSTRAIS}

As amostras analisadas foram retiradas dos terços superiores de vertentes localizadas na bacia do Igarapé Belmont. Essa bacia abrange a porção norte da cidade de Porto Velho - Rondônia (Figura 2).

A área de coleta das amostras apresenta um relevo Denudacional Estrutural Tabular de fraco grau de entalhamento dos vales e média dimensão interfluvial - (DEt 14) (SANTOS; DELLA JUSTINA; FERREIRA, 2012). O solo das áreas das amostras é classificado como Latossolo Vermelho Amarelo Distrófico, segundo Rondônia (2000). Foram realizadas classificações granulométricas das amostras com finalidade de subsidiar as análises de secagem dos solos (Quadro 2). 
Figura 2 - Localização da coleta de amostras de solo

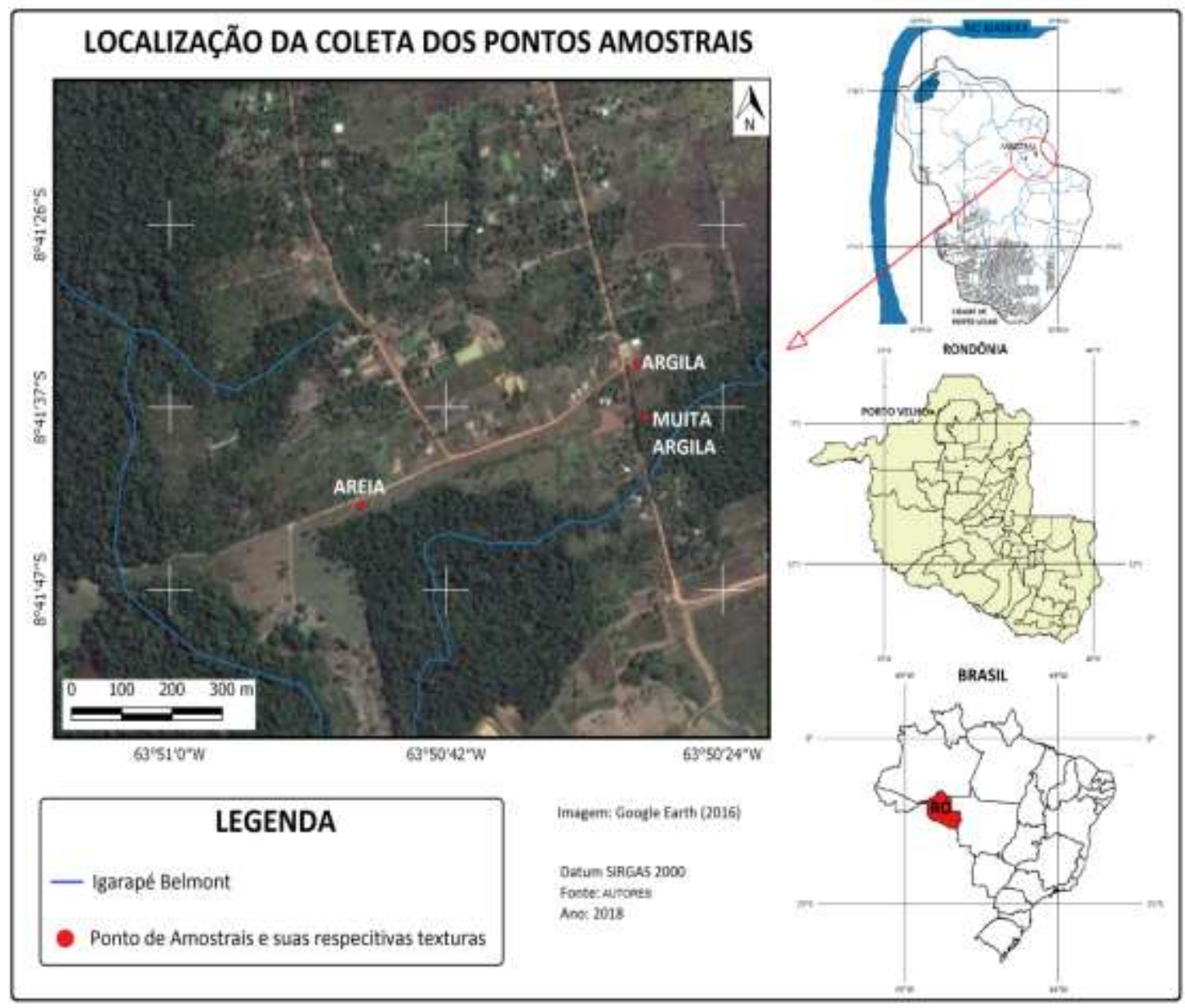

Fonte: Autores.

Quadro 2 - Granulometria e textura das amostras das três áreas em análise

\begin{tabular}{|c|c|c|c|c|c|c|}
\hline Amostras & Coordenadas & $\begin{array}{c}\text { Areia } \\
\text { Grossa } \\
(\%)\end{array}$ & $\begin{array}{c}\text { Areia } \\
\text { Fina } \\
(\%)\end{array}$ & $\begin{array}{c}\text { Silte } \\
(\%)\end{array}$ & $\begin{array}{c}\text { Argila } \\
(\%)\end{array}$ & Textura \\
\hline $\mathbf{1}$ & $08^{\circ} 41^{\prime} 34.1^{\prime \prime} \mathrm{S} 63^{\circ} 50^{\prime} 29.4^{\prime \prime} \mathrm{W}$ & 1,79 & 23,98 & 17,47 & 56,76 & Argilosa \\
\hline $\mathbf{2}$ & $08^{\circ} 41^{\prime} 34.0^{\prime \prime S} 63^{\circ} 50^{\prime} 29.3^{\prime \prime} \mathrm{W}$ & 1,80 & 24,00 & 17,50 & 56,70 & Argilosa \\
\hline $\mathbf{3}$ & $08^{\circ} 41^{\prime} 34.1^{\prime \prime} \mathrm{S} 63^{\circ} 50^{\prime} 29.2^{\prime \prime} \mathrm{W}$ & 1,81 & 24,02 & 17,53 & 56,64 & Argilosa \\
\hline $\mathbf{4}$ & $08^{\circ} 41^{\prime} 36.5^{\prime \prime} \mathrm{S} 63^{\circ} 50^{\prime} 28.9^{\prime \prime} \mathrm{W}$ & 6,29 & 13,88 & 18,77 & 61,06 & Muita Argilosa \\
\hline $\mathbf{5}$ & $08^{\circ} 41^{\prime} 36.4^{\prime \prime} \mathrm{S} 63^{\circ} 50^{\prime} 28.6 \mathrm{~W} \mathrm{~W}$ & 6,30 & 13,90 & 18,80 & 61,00 & Muita Argilosa \\
\hline $\mathbf{6}$ & $08^{\circ} 41^{\prime} 36.4^{\prime \prime} \mathrm{S} 63^{\circ} 50^{\prime} 28.7 \mathrm{~W} \mathrm{~W}$ & 6,31 & 13,92 & 18,83 & 60,94 & Muita Argilosa \\
\hline $\mathbf{7}$ & $08^{\circ} 41^{\prime} 42.4^{\prime \prime} \mathrm{S} 63^{\circ} 50^{\prime} 48.5^{\prime \prime} \mathrm{W}$ & 76,99 & 7,48 & 2,47 & 13,06 & Areia \\
\hline $\mathbf{8}$ & $08^{\circ} 41^{\prime} 42.3^{\prime \prime} \mathrm{S} 63^{\circ} 50^{\prime} 48.8^{\prime \prime} \mathrm{W}$ & 77,00 & 7,50 & 2,50 & 13,00 & Areia \\
\hline $\mathbf{9}$ & $08^{\circ} 41^{\prime} 42.3^{\prime \prime} \mathrm{S} 63^{\circ} 50^{\prime} 48.9^{\prime \prime} \mathrm{W}$ & 77,01 & 7,52 & 2,53 & 12,94 & Areia \\
\hline
\end{tabular}

Fonte: Autores.

\section{MATERIAIS E MÉTODO}

Foram retiradas três amostras de solo a uma profundidade de 0 - 20 centímetros das três vertentes em análise, sob uma área delimitada de $2 \mathrm{~m}^{2}$. Essas amostras foram envasadas em filmes de PVC. No Laboratório de Solos da Universidade Federal de 
Rondônia, as amostras foram secas ao ar por uma semana e peneiradas em peneira de número 40 (malha), 0,42mm, com o objetivo de obter Terra Fina Seca ao Ar (TFSA).

Todas as amostras foram umedecidas com $20 \mathrm{ml}$ de água para proceder ao processo de desidratação, de forma simultânea, na estufa, devido à homogeneidade da distribuição da temperatura em seu interior e de forma singular para o micro-ondas, em virtude da heterogeneidade da dissipação das ondas eletromagnéticas e do método de análise no aparelho micro-ondas, que é por unidade amostral, posicionada no centro do prato da cavidade do aparelho (BUSKE et al., 2014).

Para a secagem em estufa, utilizou-se a técnica gravimétrica de umidade de solo da EMBRAPA (1997). Para isto, foi utilizada a equação da umidade gravimétrica preconizada por Klein (2014), Equação 1:

$$
U_{g}(\%)=\frac{\left(M_{u}-M_{s}\right) \cdot 100}{M_{s}}
$$

Onde:

$U_{g}=$ Umidade Gravimétrica em percentual

$M_{u}=$ Massa úmida da amostra em gramas

$M_{s}=$ Massa seca da amostra em gramas.

Para este estudo foi utilizado um peso inicial amostral de $100 \mathrm{~g}$ com objetivo de simplificar as análises, pois o próprio percentual da umidade da amostra é a diferença de peso da amostra úmida e seca. Essas amostras foram acondicionadas em vasilhames (cadinhos) de argila. Para cada amostra de solo, foram repetidas três vezes o procedimento de secagem com objetivo de obter-se a média de umidade de cada textura de solo.

Para a secagem das amostras em forno micro-ondas, foram utilizados dois aparelhos, ambos de frequência de $2,45 \mathrm{GHz}$ (características no Quadro 3), em potência máxima (100\%), por um tempo de cinco minutos. As amostras tiveram sua temperatura controlada em $\pm 25^{\circ} \mathrm{C}$. antes de iniciar a desidratação. Os cadinhos com amostras foram postos no centro do prato da cavidade do aparelho com objetivo de ter o máximo de bombardeamento das micro-ondas nas amostras.

Para a calibração da potência real de cada aparelho de micro-ondas, dada ao decaimento da força de emissão de ondas da válvula magnetron, foi utilizado o método de Souza, Nogueira e Rassini (2002), que relatam que a calibração é importante, pois possibilita aferir a reprodutibilidade do aquecimento do aparelho em potência real de trabalho. Deste modo foram realizadas as etapas: 
Determinação da Umidade de Solo pelos Métodos Estufa e Forno Micro-Ondas em Diferentes...

1 - Manter 15 litros de água sob temperatura de $\pm 23^{\circ} \mathrm{C}$.

2 - Encher um litro de água em um vasilhame plástico (polipropileno ou policarbonato), pois os vidros absorvem as micro-ondas, não sendo recomendado para tal ação.

3 - Medir a temperatura inicial (Ti) da água, que deve ser de $\pm 23^{\circ} \mathrm{C}$.

4 - Colocar o vasilhame plástico com água tampado na cavidade do forno micro-ondas e aquecê-lo por um período de dois minutos em potência de 100\% (máxima potência do aparelho).

5 - Retirar o vasilhame plástico com água do forno e agitá-lo vigorosamente, até que a água homogenize sua temperatura em todo o espaço do frasco e registrar a temperatura final (Tf), em um prazo máximo de 30 segundos.

6 - Repetir os procedimentos anteriores com a potência do aparelho de micro-ondas em $80 \%, 60 \%, 40 \%$ e $20 \%$.

7 - Devem-se realizar três medidas da temperatura final para cada potência, a fim de obter uma média de aquecimento dada à potência.

8 - Calcular a potência real do aparelho de micro-ondas de acordo com a equação (2):

onde:

$$
\mathrm{P}=34,86 \cdot(\mathrm{Tf}-\mathrm{Ti})
$$

$\mathrm{P}=$ Potência real do aparelho $\left(\mathrm{W} \cdot \mathrm{J} \cdot \mathrm{seg}^{-1}\right)$

$\mathrm{Tf}=$ Temperatura final em $\left({ }^{\circ} \mathrm{C}\right)$

$\mathrm{Ti}=$ Temperatura inicial em $\left({ }^{\circ} \mathrm{C}\right)$.

Quadro 3 - Características técnicas dos aparelhos de micro-ondas

\begin{tabular}{|l|c|c|}
\hline \multicolumn{1}{|c|}{ Nome } & Micro 700 & Micro 900 \\
\hline Marca / Modelo & Electrolux / MEF 28 & Philco / PME 25 \\
\hline Volume Total & 18 litros & 25 litros \\
\hline Volume Útil & 12 litros & 14 litros \\
\hline Potência Nominal (consumo) & 1140 watts & 1400 watts \\
\hline Potência Útil (saída) & 700 watts & 900 watts \\
\hline Eficiência & A (54\%) & A (55\%) \\
\hline
\end{tabular}

Fonte: INMETRO, 2017.

Deve-se destacar que, para a calibração das potências, os aparelhos de micro-ondas devem ser conectados em uma rede de tensão que não varie \pm 2 volts, sob risco de interferir no rendimento dos aparelhos. Caso haja variação acima deste valor de tensão deve ser utilizado um estabilizador de rede elétrica.

Os resultados da secagem de solo em estufa e micro-ondas foram correlacionados utilizando os métodos estatísticos de Pearson $\left(\mathrm{R}^{2}\right)$ e Teste $\mathrm{T}$ (Student), bi-caudal, ao nível de confiança de 95\%, para o cálculo de precisão dos valores entre estufa e micro-ondas. A avaliação da textura das amostras foi realizada por meio do método granulométrico da EMBRAPA (1997). 
Para a análise da existência de óxi-hidróxido de ferro, foi procedida a extração da matéria orgânica das amostras por incineração em mufla a $550^{\circ}$ Celsius, por três horas, seguindo os preceitos de Carmo e Silva (2012) a fim de analisar a cor do solo resultante da calcinação por comparação em Carta de Munsell. Após classificação das cores, foi utilizado para discriminar os tons de vermelho das amostras o Índice de Vermelho, que utiliza a equação 3, usando os parâmetros obtidos na Carta de Munsell em matrizes YR, de solos vermelhos amarelos (HURST, 1977; TORRENT; SCHWERTMANN; SCHULZE, 1980).

$$
I V=\frac{(10-h) \cdot c}{v}
$$

Onde:

IV = Índice de Vermelho

$\mathrm{h}=$ número que precede somente as siglas YR da matriz

$\mathrm{c}=$ Croma

$\mathrm{v}=$ Valor.

Os valores do Índice de Vermelho sempre serão maiores em solos com maior teor de hematita e menores em solos com predomínio de goethita (BARRÓN; TORRENT, 1986).

\section{RESULTADOS E DISCUSSÃO}

A análise granulométrica das amostras demonstra características específicas das texturas, o que aumenta o universo de comparação/análise das amostras (Quadro 1; Figura 3). Ao extrair amostras dos referidos pontos verificou-se textura muito argilosa, e presença de nódulos de petroplintita a partir de $20 \mathrm{~cm}$ de profundidade, com tonalidades avermelhadas a roxas.

Constata-se que, através dos dados texturais, as amostras que irão melhor reagir com as micro-ondas serão as muito argilosas e a de menor reação serão as amostras arenosas, segundo Tavares et al. (2008); Miranda et al. (2012); Buske et al. (2014) e Cremon et al. (2014). Percebe-se nas amostras muito argilosas um aumento linear para a textura mais fina o que difere da amostra argilosa, que não apresenta linearidade de textura.

A classificação das cores das amostras pela carta de Munssel e do Índice de Vermelho não diferiram entre as amostras da mesma vertente (amostras $A, B$ e C) que apresentaram cores que variam do 2,5 YR à 7,5 YR (Quadro 4 e Figura 3).

De acordo com os preceitos de Barrón e Torrent, (1986) a amostra Arenosa apresenta a maior quantidade de óxido de ferro das amostras, e deverá interagir muito mais com as micro-ondas, refratando-as, do que as amostras Muito Argilosa e Argilosa, que apresentaram menor concentração de óxido de Ferro. 
Quadro 4 - Classificação de cores dos solos amostrais

\begin{tabular}{|c|c|c|c|}
\hline Amostras & Textura & Cor (Munssel) & Índice de Vermelho \\
\hline 1,2 e 3 & Argilosa & $2,5 Y R(6 / 8)$ & 2,14 \\
\hline 4,5 e 6 & Muito Argilosa & $5 Y R(6 / 8)$ & 6,66 \\
\hline 7,8 e 9 & Arenosa & $7,5 Y R(7 / 6)$ & 10,00 \\
\hline
\end{tabular}

Fonte: Autores.

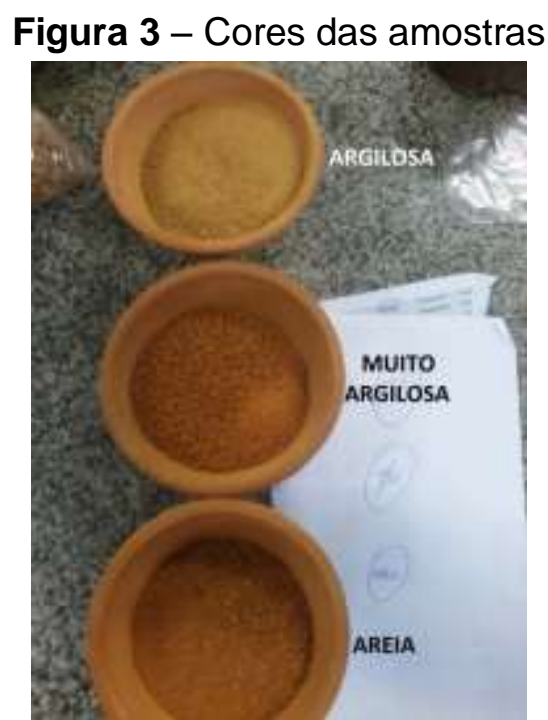

Fonte: Autores.

A calibração dos fornos micro-ondas demonstrou uma diferença já esperada nos rendimentos dos fornos. O Micro 900 apresentou como potência real de $519,41 \mathrm{w} \cdot \mathrm{j} \cdot \mathrm{seg}^{-1} \mathrm{e}$ o Micro 700 apresentou a potencia real de 469,21 w $j \cdot \mathrm{seg}^{-1}$, com diferença de 50,20 $w \cdot j \cdot \mathrm{seg}^{-1}$ a menos do que o Micro 900 (M900). Contudo o Micro 700 (M700) apresenta menor cavidade, o que condiciona uma maior concentração de ondas em um só ponto. Verificam-se diferenças sutis de secagem entre os modos estufa e micro-ondas (Quadro 5 e Figura 4).

Os fornos micro-ondas variaram em média $0,48 \%$ nos valores de secagem de amostras de solo, comparando-se com a estufa. O Micro 700 retirou menos água do solo em comparação ao Micro 900 e a estufa em todas as amostras. Já os resultados do Micro 900 comparados aos valores de secagem da estufa evidenciaram que este micro-onda retirou mais água das amostras, com exceção das amostras 4, 5 e 6 (muito argilosa), que secaram menos do que o método padrão, o que torna a previsão antagônica, pois essas amostras deveriam secar mais do que as outras, já que são de texturas diferentes e reagem muito mais às micro-ondas, dado ao teor mais elevado de água. Essa deficiência ocasionou uma diferença média de 0,56\% a menos de desidratação, do que a estufa (Quadro 4), atestandose uma significativa discrepância de valores percentuais de umidade. 
Quadro 5 - Peso de entrada e saída das amostras e percentual da umidade perdida.

\begin{tabular}{|c|c|c|c|c|c|c|c|c|c|c|}
\hline Amostra & $\begin{array}{c}\text { Peso } \\
\text { de } \\
\text { entrada } \\
\text { estufa }\end{array}$ & $\begin{array}{c}\text { Peso } \\
\text { de } \\
\text { saída } \\
\text { estufa }\end{array}$ & $\begin{array}{l}\text { Umidade } \\
\text { perdida } \\
\text { estufa }\end{array}$ & \begin{tabular}{|c|} 
Peso de \\
entrada \\
M700
\end{tabular} & $\begin{array}{l}\text { Peso } \\
\text { de } \\
\text { saída } \\
\text { M700 }\end{array}$ & $\begin{array}{c}\text { Umidade } \\
\text { perdida } \\
\text { M700 }\end{array}$ & $\begin{array}{c}\text { Peso } \\
\text { de } \\
\text { entrada } \\
\text { M900 }\end{array}$ & $\begin{array}{c}\text { Peso } \\
\text { de } \\
\text { saída } \\
\text { M900 } \\
\end{array}$ & $\begin{array}{l}\text { Umidade } \\
\text { perdida } \\
\text { M900 }\end{array}$ & Textura \\
\hline 1 & $100 \mathrm{~g}$ & $81,79 \mathrm{~g}$ & & $100 \mathrm{~g}$ & $81,85 \mathrm{~g}$ & & $100 \mathrm{~g}$ & $81,30 \mathrm{~g}$ & & Argilosa \\
\hline 2 & $100 \mathrm{~g}$ & $81,34 \mathrm{~g}$ & & $100 \mathrm{~g}$ & $81,63 \mathrm{~g}$ & 18,3 & $100 \mathrm{~g}$ & $81,18 \mathrm{~g}$ & 2\% & Argilosa \\
\hline 3 & $100 \mathrm{~g}$ & $81,27 g$ & & $100 \mathrm{~g}$ & $81,71 \mathrm{~g}$ & $18,29 \%$ & $100 \mathrm{~g}$ & $81,03 g$ & $8,97 \%$ & Argilosa \\
\hline 4 & $100 \mathrm{~g}$ & $80,14 \mathrm{~g}$ & & $100 \mathrm{~g}$ & $80,95 \mathrm{~g}$ & & $100 \mathrm{~g}$ & $80,78 \mathrm{~g}$ & & \\
\hline 5 & $100 \mathrm{~g}$ & $80,01 \mathrm{~g}$ & & $100 \mathrm{~g}$ & $80,82 \mathrm{~g}$ & & $100 \mathrm{~g}$ & $80,55 \mathrm{~g}$ & & $\begin{array}{c}\text { Muito } \\
\text { Argilosa }\end{array}$ \\
\hline 6 & $100 \mathrm{~g}$ & $79,87 \mathrm{~g}$ & & $100 \mathrm{~g}$ & $80,76 \mathrm{~g}$ & $19,24 \%$ & $100 \mathrm{~g}$ & $80,39 \mathrm{~g}$ & $19,61 \%$ & \\
\hline 7 & $100 \mathrm{~g}$ & $83,20 \mathrm{~g}$ & $16,80 \%$ & $100 \mathrm{~g}$ & $84,00 \mathrm{~g}$ & $16,00 \%$ & $100 \mathrm{~g}$ & $82,95 \mathrm{~g}$ & $17,05 \%$ & Arenosa \\
\hline 8 & $100 \mathrm{~g}$ & $83,12 \mathrm{~g}$ & & $100 \mathrm{~g}$ & $83,20 \mathrm{~g}$ & $16,80 \%$ & $100 \mathrm{~g}$ & $82,87 \mathrm{~g}$ & $17,13 \%$ & Arenosa \\
\hline 9 & $100 \mathrm{~g}$ & $83,04 \mathrm{~g}$ & $16,96 \%$ & $100 \mathrm{~g}$ & $83,12 \mathrm{~g}$ & $16,88 \%$ & $100 \mathrm{~g}$ & $82,79 \mathrm{~g}$ & $17,21 \%$ & Arenosa \\
\hline
\end{tabular}

Fonte: Autores.

Figura 4 - Gráfico comparativo de desidratação percentual das amostras

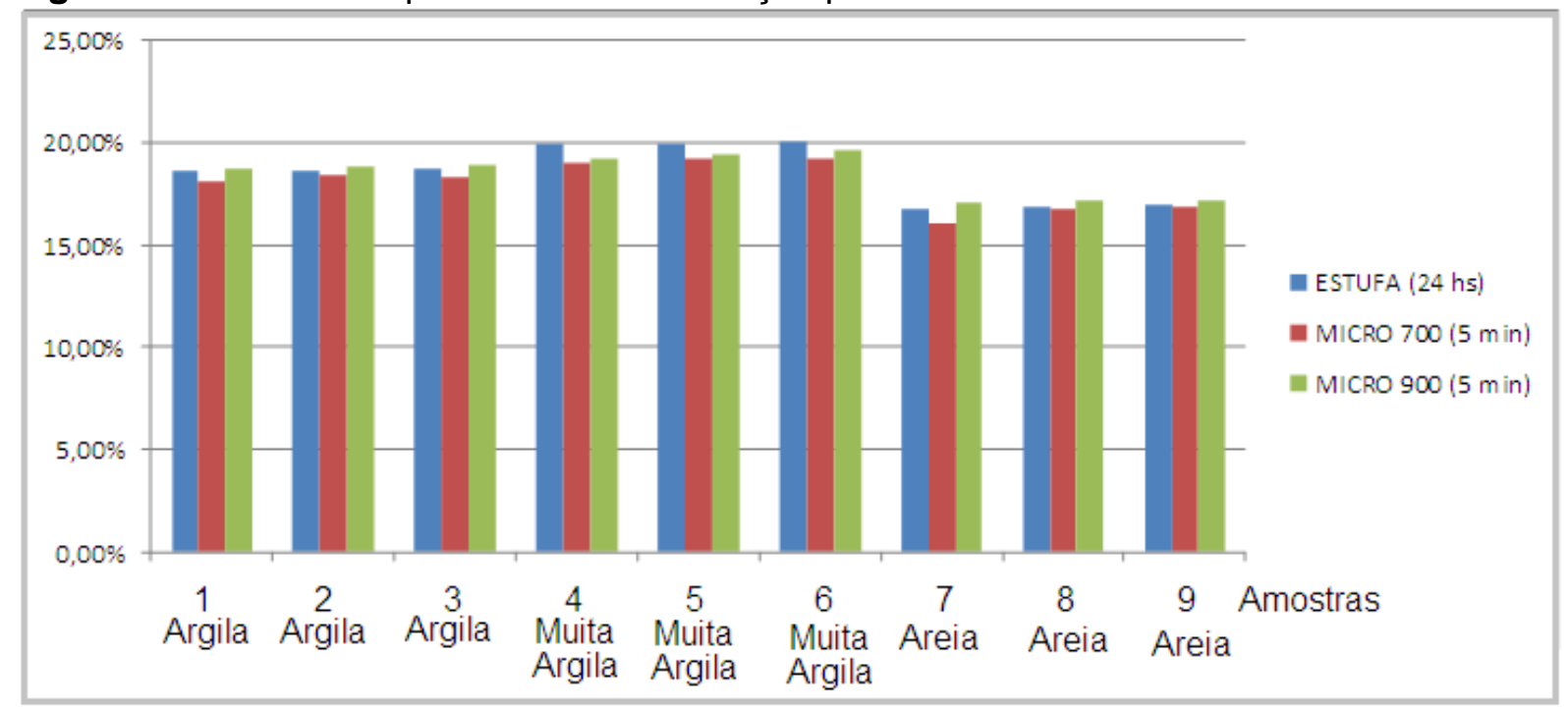

Fonte: Autores.

Uma das possíveis causas dessa baixa desidratação, seguindo os preceitos de Wong (1975); Tinga (1989); Tavares et al. (2008); Koleini e Barani (2012) e Cremon et al. (2014), pode estar relacionada com o elevado teor de óxido de ferro nestas amostras, que associada ao volume maior da cavidade do forno (14L), desencadeou uma maior dissipação das micro-ondas ao ser bombardeado, ocasionando uma maior deficiência no processo de movimentação dos dipolos da água, neste solo muito argiloso. Nesta situação, fornos microondas de menor volume de cavidade sofrem menos dissipação das ondas, dado ao seu pequeno espaço para o bombardeamento eletromagnético ondular. 
Determinação da Umidade de Solo pelos Métodos Estufa e Forno Micro-Ondas em Diferentes...

O mesmo pode ser verificável na Figura 4. O Micro 700, apesar de extrair menos umidade das amostras em relação à estufa, apresentou uma deficiência muito maior na secagem da amostra 4, 5 e 6 (muito argilosa), média de 0,83\% a menos do que nas amostras da estufa, que é também um valor inferior ao percentual de secagem das outras duas amostras de textura diferentes, secas no Micro 700. Uma forma para contornar essa deficiência seria utilizar um aparelho de maior potência real ou utilizar um tempo maior para secagem.

Ao comparar as amostras arenosas, que são as que apresentam maior quantidade de óxido de ferro, verifica-se que a discrepância entre os valores dos fornos micro-ondas com a estufa é menor, com destaque para as amostras 7, 8 e 9 (areia) do Micro 700, que foi a que apresentou menor variação de percentual de secagem entre as amostras. Isto ocorre devido à textura das amostras que, por serem arenosas, contém menos água entre seus grãos do que as amostras argilosas. Além disto, os grãos interagem apenas em um lado da senoide das micro-ondas, devido a serem partículas monopolares, vibrando menos e consequentemente secando menos, o que pactua-se com o entendimento de Tavares et al. (2008) e Miranda et al. (2008).

O tempo de cinco minutos de secagem nos micro-ondas foi suficiente para retirar a água das amostras ao mesmo nível da estufa, mesmo apresentando dispersão de ondas eletromagnéticas, devido à presença de óxido de ferro que as refratam.

Ao correlacionar e testar os níveis de significância dos valores de secagem entre a estufa e os micro-ondas verifica-se que as discrepâncias de tores de umidade apresentadas entre os aparelhos de micro-ondas e estufa revelam baixa significância, mesmo para amostras com elevado percentual de óxidos de ferro. A correlação entre os processos de secagem de solo também corroborou para o mesmo resultado, em uma elevada correlação (Quadro 6).

Quadro 6 - Correlações e significâncias de valores de secagem entre estufa e fornos microondas

\begin{tabular}{|c|c|c|c|c|}
\hline Textura & $\begin{array}{c}\text { Micro 700 } \\
\text { Correlação }\end{array}$ & $\begin{array}{c}\text { Micro 900 } \\
\text { Correlação }\end{array}$ & $\begin{array}{c}\text { Micro 700 Significância } \\
\mathbf{( 0 , 0 5 \% )}\end{array}$ & $\begin{array}{c}\text { Micro 900 Significância } \\
\mathbf{( 0 , 0 5 \% )}\end{array}$ \\
\hline Argilosa & 0,98 & 0,99 & 0,40 & 0,94 \\
\hline Muito Argilosa & 0,96 & 0,96 & 0,41 & 0,91 \\
\hline Arenosa & 0,97 & 0,97 & 0,40 & 0,93 \\
\hline
\end{tabular}

Fonte: Autores.

Isto indica que os valores de secagem entre estufa e micro-ondas são similares, e a incompatibilidade apresentada está dentro do nível de tolerância aceitável, desde que o modo de secagem via micro-ondas obedeça ao tempo de cinco minutos de secagem e uma potência média real de $494,31 w \cdot j \cdot \mathrm{seg}^{-1}$ do aparelho. O nível significância médio de 
diferenças de valores das amostras entre os micro-ondas pelo Teste $T$ foi de 0,40 e 0,93 para o Micro 700 e Micro 900, respectivamente.

Ao observar a pequena dissonância do percentual de umidade das amostras argilosas dos fornos micro-ondas com a estufa, em relação ao nível de óxido de ferro (Quadro 7), verificou-se a influência dos óxidos de ferro das amostras nas micro-ondas.

Quadro 7 - Discrepância de umidade dos aparelhos micro-ondas em comparação com os valores de estufa e em relação ao índice de óxidos de ferro

\begin{tabular}{|c|c|c|c|c|}
\hline Amostras & Micro 700 & Micro 900 & Índice Vermelho & Textura \\
\hline $\mathbf{1}$ & $-0,43 \%$ (secou menos) & $0,12 \%$ (secou mais) & 2,14 & Argilosa \\
\hline $\mathbf{2}$ & $-0,29 \%$ (secou menos) & $0,16 \%$ (secou mais) & 2,14 & Argilosa \\
\hline $\mathbf{3}$ & $-0,45 \%($ secou menos) & $0,23 \%$ (secou mais) & 2,14 & Argilosa \\
\hline $\mathbf{4}$ & $-0,86 \%($ secou menos) & $-0,69 \%$ (secou menos) & 6,66 & Muito Argilosa \\
\hline $\mathbf{5}$ & $-0,81 \%($ secou menos) & $-0,54 \%$ (secou menos) & 6,66 & Muito Argilosa \\
\hline $\mathbf{6}$ & $-0,83 \%($ secou menos) & $-0,46 \%$ (secou menos) & 6,66 & Muito Argilosa \\
\hline
\end{tabular}

Fonte: Autores.

A correlação entre a diferença de umidade e o Índice de Vermelho demonstrou ser negativa, $(-0,97)$ para as amostras do Micro 700 e $(-0,97)$ para as amostras do Micro 900. Percebe-se que o aumento de óxidos de ferro e a diminuição da eficiência na desidratação de amostras argilosas são grandezas inversas.

A análise de significância, (95\%), dos valores entre o Índice de Vermelho e a debilidade de secagem de água dos aparelhos de micro-ondas entre o método padrão, apresentou valores de $0,001 \%$ de significância em ambos os valores dos aparelhos microondas, confirmando que há uma pequena influência dos óxidos de ferro na dissipação das micro-ondas, quando há bombardeamento dessas ondas em solos de textura argilosa.

\section{CONCLUSÃO}

O processo de secagem de solos é um importante método de análise física, com amplo uso na Pedologia, Geomorfologia, Biogeografia, Agronomia e áreas que apresentam interesse em estudos de solo. Para tanto se tem como método padrão de secagem a estufa, esta apresenta boa eficiência em desidratação, porém é um método lento e com excessivo consumo de eletricidade. O método alternativo de secagem usando forno micro-ondas apresentou ser uma ótima alternativa de secagem de solo. Ao utilizar fornos micro-ondas de diferentes potências de saída, contudo, com Potência Real Média de 494,31 w $\mathrm{j} \cdot \mathrm{seg}^{-1}$, em um tempo de cinco minutos, utilizando 100 gramas por amostra, atestam-se percentuais de secagem com elevada correlação positiva com o método Estufa, em diferentes tipos de textura de solos, como arenoso, argiloso e muito argiloso. Contudo, é recomendando a 
Determinação da Umidade de Solo pelos Métodos Estufa e Forno Micro-Ondas em Diferentes...

observação das pequenas deficiências de secagem de solos de texturas argilosas, ricos em óxido de ferro, dado que os óxidos de ferro desencadeiam uma maior dissipação das microondas, ocasionando uma maior deficiência no processo de movimentação dos dipolos da água presente nestes solos e consequentemente desidratam com valores inferiores ao método tradicional de secagem de solos.

\section{REFERÊNCIAS}

BARBOZA, A. C. R. N.; CRUZ, C. V. M. S.; GRAZIANI, M. B.; LORENZETTI, M. C. F.; SABADINI, E. Aquecimento em forno de micro-ondas/desenvolvimento de alguns conceitos fundamentais. Revista Química Nova, v. 24, n. 6, p. 901-904, 2001.

BARRÓN, V.; TORRENT, J. Use of the kubelka-munk theory to study the influence of iron on soil colour. Journal of Soil Science, Oxford, v. 37, p. 499-510, 1986.

BERTELI, M. E. Estudo comparativo de processos de secagem de sólidos granulados com e sem assistência de microondas. 2005. Dissertação (Mestrado) - Faculdade de Engenharia de Alimentos. Universidade Estadual de Campinas, Campinas - SP, 2005.

BUSKE, T.; ROBAINA, A.; PEITER, M.; TORRES, R.; ROSSO, R.; BRAGA, F. Determinação da umidade do solo por diferentes fontes de aquecimento. Revista Irriga UNESP, Botucatu, v. 19, n. 2, p. 315-324, abr./jun. 2014.

CARMO, D. L.; SILVA, C. A. Métodos de quantificação de carbono e matéria orgânica em resíduos orgânicos. Revista Brasileira de Ciência do Solo, Rio de Janeiro, v. 36, p. 1211 1220, 2012.

CORREIA, A. M.; KER, J. C.; BARRÓN, V; FONTES, M. P F.; TORRENT, J.; CURI, N. Caracterização de óxidos de ferro de solos do ambiente tabuleiros costeiros. Revista Brasileira de Ciência do Solo, Rio de Janeiro, v. 32, p. 1017-1031, 2008.

CREMON, C.; LONGO, L.; MAPELI, N. C.; SILVA, L. A. M.; MENDES, W. Determinação da umidade de diferentes solos do Pantanal Matogrossense via micro-ondas e método padrão. Revista Agrarian, Dourados - MS, v. 7, n. 24, p. 280-288, 2014.

DIAS, L. G. Estudo do processo de secagem em estufa e por micro-ondas de compósitos cerâmicos de argila e resíduos de estreatito. 2013. Dissertação (Mestrado) Programa de Pós-Graduação em Engenharia da Energia. Universidade Federal de São João Del Rei. São João Del Rei - MG, 2013.

EMBRAPA - EMPRESA BRASILEIRA DE PESQUISA AGROPECUÁRIA -Centro Nacional de Pesquisa de Solo. Manual de métodos de análise de solo. Rio de Janeiro, 1997.

EQUIPEX, Instrumentos Analíticos. Dicas para Escolha Certa de Estufa para Seu Laboratório, 2018. Disponível em: http://www.Equipexinstrumentos.com.br. Acesso em: 13 fev. 2019.

FERNANDES, R. B. A.; BARRÓN, V.; TORRENT, J.; FONTES, M. P. F. Quantificação de Óxidos de Ferro de Latossolos Brasileiros por Espectroscopia de Refletância Difusa.

Revista Brasileira de Ciência do Solo, Rio de Janeiro, v. 28, p. 245-257, 2004.

HURST, V. J. Visual estimation of iron in saprolite. Geologic Society American, Bull, v. 88, p. 174-176, 1977.

INMETRO - INSTITUTO NACIONAL DE METEOROLOGIA, QUALIDADE E TECNOLOGIA.

Programa brasileiro de etiquetagem: fornos microondas. Brasília: INMETRO, 2017.

Disponível em: http://www.inmetro.gov.br/consumidor/pbe/fornos_de_micro-ondas.pdf.

Acesso em: 12 nov. 2017. 
KLEIN, V. A. Física do solo. Passo Fundo - RS: Universidade de Passo Fundo, 2014.

KOLEINI, J.; BARANI, K. Microwave heating applications in mineral processing. Intech. Chapter 4. 2012. Disponível em: http://dx.org/10.5772/45750. Acesso em: 5 jan. 2018.

MAGALHÃES, R. S.; LIMA, R. M. F.; SOUZA, H. A. O uso de microondas para determinação de umidade de bauxita. Revista Escola de Minas, Minas Gerais, v. 56, n. 4, p. 255-259, out./dez. 2003.

MILLER, R. J.; SMITH, R. B.; BIGGAR, J. W; Soil water content: microwave oven method. Proceedings Soil Science Society of America, Madison, v. 38, n. 3, p. 535-537, 1974.

MIRANDA, E.; MARTINS, G.; CARMO, F.; LIMA, L.; SILVA, F. Uso do Forno Micro-ondas na Determinação da Umidade de um Solo Franco - Siltoso. In: WORKSHOP INTERNACIONAL DE INOVAÇÕES TECNOLÓGICAS NA IRRIGAÇÃO, 2012, Fortaleza. Anais [...]. Fortaleza - CE, 2012. p. 201-203.

MIRANDA, E.; MONTEIRO, R.; SANTOS, F.; LEITE, K.; RODRIGUES, A.; OLIVEIRA, D. Determinação da Umidade do Solo no Forno Micro-ondas em Diferentes Potências. In: SIMPÓSIO BRASILEIRO SOBRE O USO MÚLTIPLO DA ÁGUA, 1., 2008, Fortaleza. Anais [...]. Fortaleza - CE, 2008. p. 329-333.

OLIVEIRA, L. F. C.; ROQUE, C. G. Determinação da umidade do solo por micro-ondas e estufa em três texturas de um latossolo vermelho-amarelo do cerrado. Revista de Agricultura Neotropical, Cassilândia - MS, v. 3, n. 4, p. 60-64, out./dez. 2016.

PAIVA NETTO, J. E.; MEDINA, H. P. O Higroscopímetro e a Determinação Rápida da Umidade Higroscópica do Solo. In: Reunião Brasileira de Ciência do Solo, 2. Campinas. 1949. Anais. Rio de Janeiro, Ministério da Agricultura, Serviço de Informação Agrícola, p. 43-70, 1953.

PEREIRA, N. R. Estudo da aplicação de micro-ondas na secagem de bananas tratadas osmoticamente. 2007. Dissertação (Mestrado) - Universidade Estadual de Campinas Faculdade de Engenharia de Alimentos - Departamento de Engenharia de Alimento, Campinas, 2007.

PICKLES, C. A.; MOURIS, J.; HUTCHEON, R. M. High temperature dielectric properties of goethite from 400 to 3000 Mhz. Journal of Materials Research - MRS, Cambridge England, v. 20, Issue 1, p. 18-29, January 2005.

RIBEIRO, K. M.; CASTRO, M. H. C.; RIBEIRO, K. D.; LIMA, P. L. T.; ABREU, L. H. P.; BAROS, L. C. Estudo Comparativo do Método Padrão da Estufa e do Método Speedy na Determinação do Teor de Agua no Solo. Brazilian Journal of Biosystems Engineering. V.12, $n^{\circ} 01$, p. 18-28, 2018.

RONDÔNIA. Governo do Estado de Rondônia. Secretaria de Estado do Desenvolvimento Ambiental - SEDAM. Zoneamento Sócio-Ecológico e Econômico do Estado de Rondônia. 2a Aproximação. (Banco de Dados Geográfico Vetorial). Porto Velho, 2000.

SALES, M.; MACÊDO, K.; MIRANDA, E.; SILVA, G.; SILVA, F.; FREITAS, J. Determinação da Umidade de Solo Argiloso Pelo Método do Forno Micro-ondas. In: CONGRESSO NORTE E NORDESTE DE PESQUISA E INOVAÇÃO - CONNEPI, 7., 2012, Palmas. Anais [...]. Palmas - TO, out. 2012.

SANTOS, S. L. M.; DELLA JUSTINA, E. E.; FERREIRA, M. M. Mapeamento geomorfológico da Bacia do lgarapé Belmont Porto Velho - RO. Revista Brasileira de Geomorfologia, v. 13, n. 3, p. 255-266, jul./set. 2012.

SCHMITT, R. Eletromagnetismo explicado: manual de sistemas sem Fio/RF, EMC e eletrônica de alta freqüência. Boston: Elsivier Science, 2002. 
SILVA, F.C.; FERREIRA, V. F.; SOUZA, M. C. B. V. Adaptação de Forno de Micro-ondas Doméstico para Realização de Reações de Transesterificação Sob Refluxo e Catálise por Argilas. Nota Técnica. Revista Química Nova, v. 29, n. 2, p. 376-380, 2006.

SOUZA, G. B.; NOGUEIRA, A. R. A.; RASSINI, J. B. Determinação de matéria seca e umidade em solos e plantas com o forno de micro-ondas doméstico. Circular Técnica 33, Empresa Brasileira em Pesquisa Agropecuária - EMBRAPA, São Carlos - SP, dez. 2002.

TAVARES, M.; CARDOSO, D.; GENTELIN, D.; GABRIEL FILHO, A.; KONOPATSKI, E. Uso do forno de microondas na determinação da umidade em diferentes tipos de solo. Revista Ciências Agrárias, Londrina, v. 29, n. 3, p. 529-538, jul./set., 2008.

TAVEIRA, M. R.; SANTOS, M.; TAVES, A. C. S.; ALVES JR, J.; EVANGELISTA, A. W. P. Determinação do conteúdo de água de solo pelo método da frigideira em um latossolo vermelho escuro. Disponível em: http://www.sbpcnet.org.br/livro/63ra/conpeex/mestrado/trabalhos-mestrado/mestradomarcio-rodrigues.pdf . Acesso em: 8 abr. 2016.

TINGA, W. R. Microwave dielectric constants of metal oxides, part 1 and part 2. electromagnetic energy reviews 2. MRJ Proceeding, v. 124, n. 33, p.349-351, 1989.

TORRENT, J.; SCHWERTMANN, U.; SCHULZE, D.G. Iron Oxide Mineralogy of Some Soils of Two River Terrace Sequences in Spain. Geoderma. v. 23, p. 191-208, 1980, Madrid.

TRINTINALHA, M. A.; GONÇALVES, A. C. A.; TORMENA, C. A.; COSTA, A. C. S.; FOLEGATTI, M. V.; SÉRGIO, P.; FREITAS, L.; REZENDE, R. Comparação dos sistemas TDR e ECHO para medida de umidade em um solo argiloso e em areia. Acta Scientiarum, Agronomy, Maringá, v. 26, n. 3, p. 353-360, 2004.

VIANA, A. N. C.; BORTONI, E. C.; NOGUEIRA E. C.; HADDAD, J.; NOGUEIRA, L. A. H.; VENTURINI, O. J.; YAMACHITA, R. A. Eficiência Energética: fundamentos e aplicações. Campinas: Universidade Federal de Itajubá, 2012.

WONG, D. Microwave dielectric constants of metal oxides at high temperature. Msc. Thesis, University of Alberta, Canada, 1975.

Recebido: outubro de 2018. Aceito: março de 2019. 